Towards Reliable and Intuitive Myoelectric Control for Hand Prostheses 



\section{Towards Reliable and Intuitive Myoelectric Control for Hand Prostheses}

PhD Thesis by

Thomas Lorrain

Department of Health Science and Technology,

Aalborg University, Denmark

River Publishers

Aalborg 
ISBN 978-87-93102-35-4 (e-book)

Published, sold and distributed by:

River Publishers

Niels Jernes Vej 10

9220 Aalborg Ø

Denmark

Tel.: +45369953197

www.riverpublishers.com

Copyright for this work belongs to the author, River Publishers have the sole right to distribute this work commercially.

All rights reserved (C) 2013 Thomas Lorrain.

No part of this work may be reproduced, stored in a retrieval system, or transmitted in any form or by any means, electronic, mechanical, photocopying, microfilming, recording or otherwise, without prior written permission from the Publisher. 
My sincere thanks to all colleagues, friends, and family members who contributed in making this work possible. 


\section{Contents}

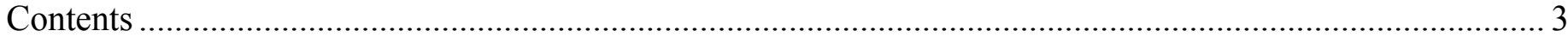

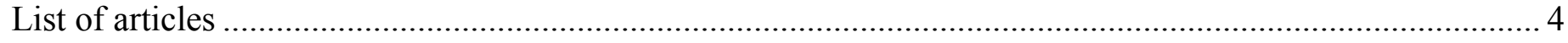

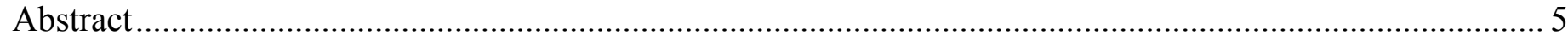

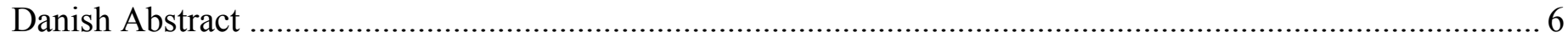

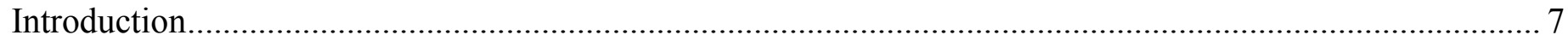

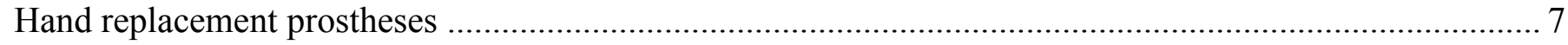

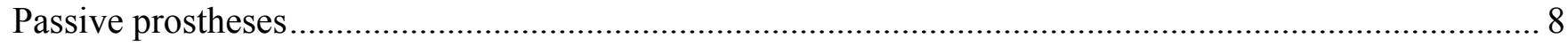

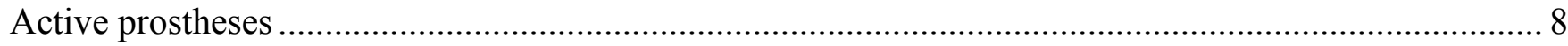

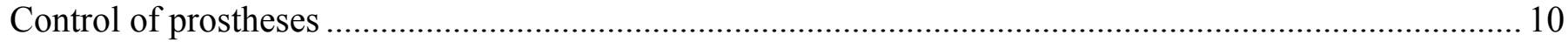

Body powered

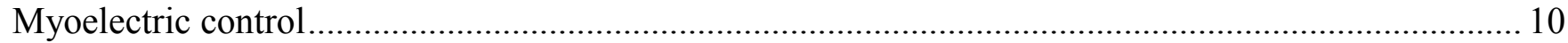

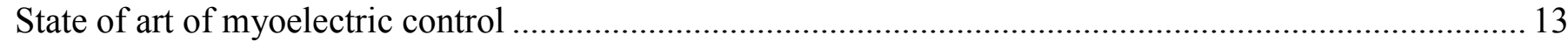

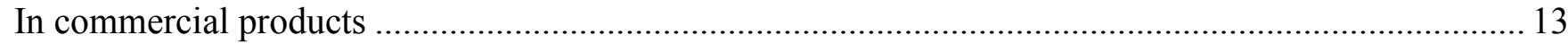

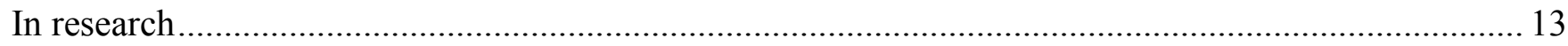

What is missing? .

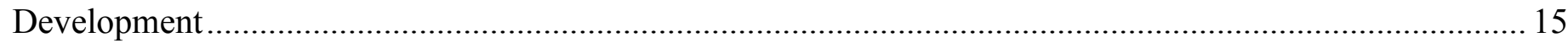

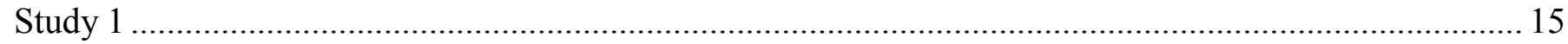

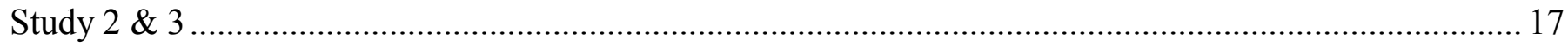

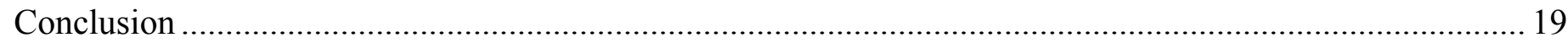

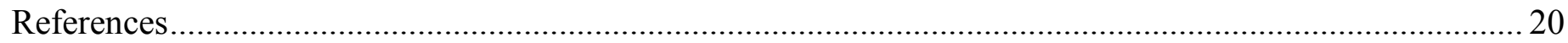

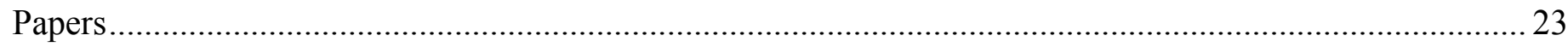




\section{List of articles}

This $\mathrm{PhD}$ thesis is based on three articles:

1. Thomas Lorrain, Ning Jiang, Dario Farina. Influence of the training set on the accuracy of surface EMG classification in dynamic contractions for the control of multifunction prostheses.

2. Thomas Lorrain, Ning Jiang, Dario Farina. A reliable control scheme using a state-based approach for myoelectric prostheses.

3. Thomas Lorrain, Ning Jiang, Dario Farina. Online proportional state-based myoelectric control. 


\section{Abstract}

The loss of a hand implies loss of motor functions and potential psychological disturbance of self-image. In order to restore some of the lost functions and help patients to overcome their trauma, great research efforts have been spent on the development of hand replacement prostheses. Despite these efforts, electrically powered prostheses available to patients remain of unnatural use and very limited dexterity, due to the limitations of the control methods available. Myoelectric control has been shown as an efficient way to control powered prostheses, however intuitive and reliable control of multiple degrees of freedom remains to be achieved.

The aim of this $\mathrm{PhD}$ thesis is to investigate the limitations of current myoelectric control strategies and provide alternative solutions towards a more functional control method.

In order to achieve this goal, the project was divided in three studies. In the first study, current myoelectric control systems showed to be able to operate on dynamic situations with satisfying performance, but at the cost of training requirements to maintain reliability. Based on these results, an alternative control system using a state-based approach was developed to overcome some of these limitations. In study 2 , the proposed system showed promising offline performance and high reliability compared to a traditional myoelectric control system. Then the system was further improved by including proportional control, and its online performance was investigated in study 3 with virtual feedback. The results showed that the proposed system allowed precise target reaching and force control during grasp, with very short training. In conclusion, this $\mathrm{PhD}$ project investigated the limitations of available myoelectric control systems, and developed an alternative control system to overcome these limitations. The proposed system showed promising performance during both offline and online analyses, and could have the potential to provide myoelectric users with a more intuitive, yet reliable control system. 


\section{Danish Abstract}

Tabet af en hånd giver sænket motorisk kontrol og en risiko for psykologiske påvirkninger så som sænket selvværd. Den eksisterende forskning har fokuseret på at udvikle håndproteser for at genopbygge nogle af de mistede motoriske kontrolfunktioner, og hjælpe patienter med at overkomme deres traume. Til trods for massiv forskning giver elektriske proteser meget begrænset behændighed for patienterne, grundet de begrænsede kontrolfunktioner som findes i disse. Myoelektriske proteser har vist sig anvendelige for at styre en elektrisk protese, dog er intuitiv og pålidelig kontrol af mange frihedsgrader stadig manglende ved disse.

Formålet med denne PhD-afhandling er at undersøge begrænsningerne ved de nuværende myoelektiske kontrolstrategier og bibringe alternative og mere kontrollerede funktionelle metoder.

For at opnå dette mål er projektet delt op i tre studier. Første studie viste at de nuværende myoelektriske kontrol systemer kunne anvendes i dynamiske situationer med tilfredsstillende resultater, dog var det nødvendigt med træning for at opretholde nøjagtighed. Baseret på disse resultater, blev der udviklet et alternativt kontrolsystem som anvendte en "state-based" tilgang for at mindske disse begrænsninger. I studie to, viste det udviklede system lovende offline resultater med stor nøjagtighed sammenlignet med de traditionelle myoelektriske kontrolsystemer. Systemet blev videreudviklet til at indeholde proportional kontrol, og systemets online resultater blev undersøgt i studie tre med virtuel feedback. Det udviklede system tillod præcise håndsudrækninger og kontrollerede greb efter meget kort træning. Dette $\mathrm{PhD}$ studie kan konkludere mangler ved de undersøgte myoelektriske kontrolsystemer, og at udviklingen af et nyt alternativt kontrolsystem overkom disse mangler. Det udviklede system viste lovende resultater ved både offline og online analyser og kan potentielt give patienter et mere intuitivt og samtidig pålideligt kontrolsystem. 


\section{Introduction}

The loss of a hand or any body part through amputation is a dramatic experience [1]. It results in a traumatism which includes loss of motor functions, uncomfortable or painful sensations [2,3], and potential psychological difficulties related to body image [4]. Efforts have been made to minimize the trauma resulting from amputations. Replacement prostheses can provide the patients with some of the lost motor function, and help maintaining the body image. Replacement prostheses can be divided in two main groups, prostheses for upper extremities, and for lower extremities. The latter ones, which are of primary importance for unassisted locomotion, have for many years successfully provided patients a way to overcome their amputation and walk unassisted in most cases. Opposed to the prostheses for lower extremities, upper extremities prostheses offer very limited compensation for the loss of an arm or hand, mainly due to the variety of tasks to realize. Biomedical engineering research has provided many types of replacement prostheses, corresponding to the variety of amputation levels. In the following, attention will be given to a specific type of amputation of upper extremities, the trans-radial amputation. This amputation corresponds to amputation between the wrist and the elbow. It can be performed on various levels, leaving each patient with a different length of stump and residual muscles situation. The variety of use of a hand and wrist is the reason of both interest and complexity of the development of replacement prostheses for these patients.

\section{Hand replacement prostheses}

Hand and wrist replacement prostheses have been used for centuries to restore appearances. With the progress in both engineering and design, replacement prostheses became more realistic and could restore some of the functions of the lost limb. Nowadays, replacement prostheses are of various types and forms: purely cosmetic prosthesis, hooks, or actuators with cosmetics wearing.

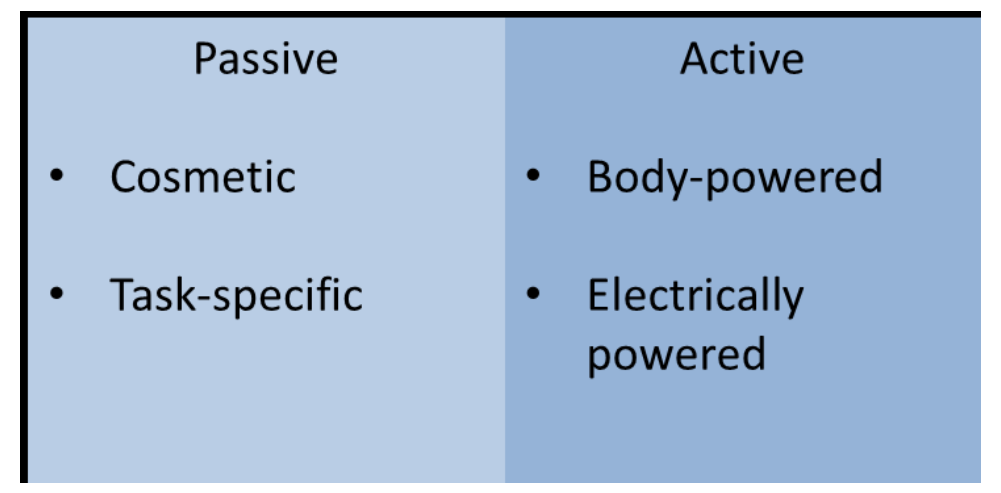

Fig.1: Type and subtype of forearm replacement prostheses. 


\section{Passive prostheses}

By definition, passive prostheses offer no active control of shape or position to the user. Most passive prostheses are purely cosmetic, representing a hand in neutral position. Passive prostheses can sometimes offer the ability to manually articulate the fingers, or be task specific. They are very commonly fitted to unilateral amputees, who use them as support during task performed by the unaffected hand. They are lighter and cheaper than most other devices, and with the progress of digital design and three dimensional modeling, cosmetics prostheses offer very good resemblance with real limbs. Along with cosmetic prostheses, some task specific prostheses are used, mainly during "recreational” activities, such as swimming or golfing.

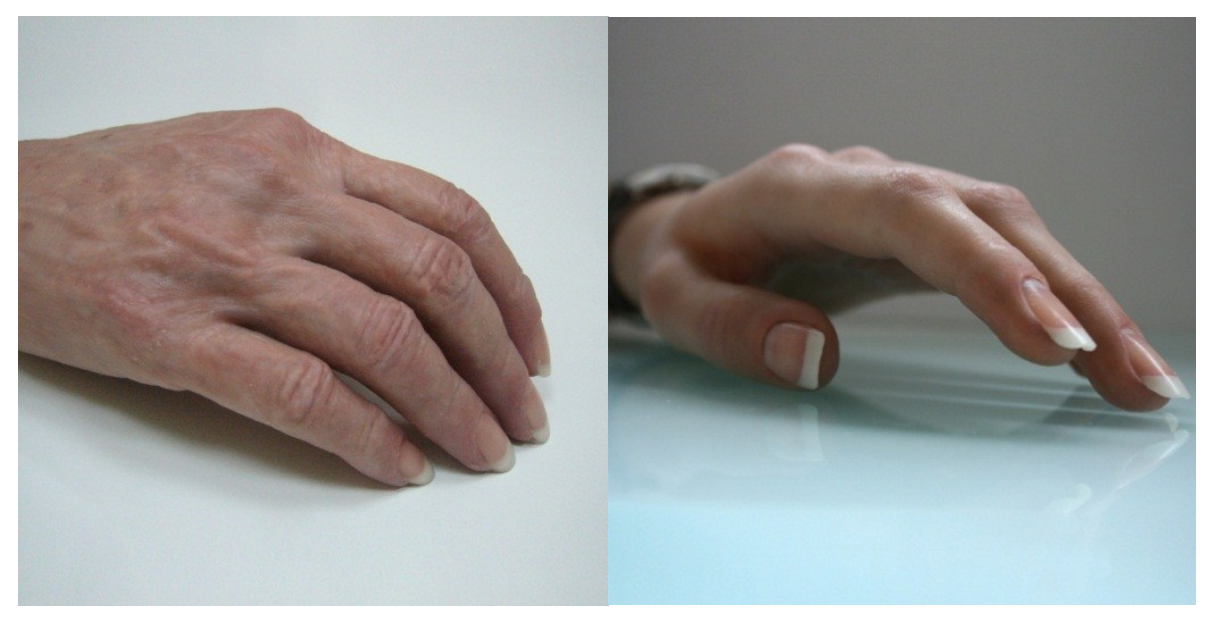

Fig.2: Examples of cosmetic hand prostheses (images courtesy of "SILAB - Art of Prosthetics")

\section{Active prostheses}

Opposed to passive prostheses, active prostheses offer some degree of control to the user. In most cases a grip function is available; while some more advanced hands can offer various grip type, and some wrist movement such as rotation or flexion. Active prostheses can be divided in two groups, body-powered, and electrically powered prostheses.

Body-powered prostheses: Body-powered prosthetic hands (or cable-operated) offer the control of one function of the hand. They are controlled by harnessing some body parts of the patient (usually shoulders or chest), and transfer the motion of the corresponding parts to the hand via cable. Body powered prostheses are of moderate weight and cost, and provide the user with some sensory feedback via force exerted on the cable. 

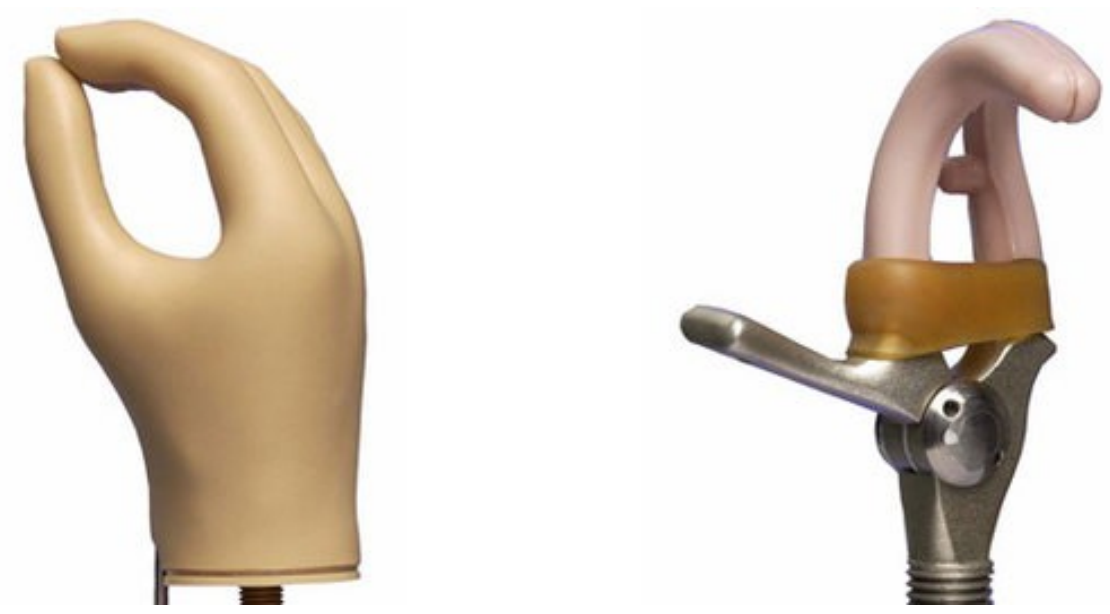

Fig. 3: Examples of body powered prosthetic devices (Images courtesy of Ottobock GmbH). (a) A cable driven hand [5]. (b) A cable driven Hook [6].

Electrically-powered prostheses: Electrically-powered prostheses are the high end of hand prosthetics. They use electric motors to produce the motion of the hand. They offer at least one grip function, completed in most cases by some active or passive wrist motions (rotation and/or flexion/extension). They are usually controlled using electromyographic signals (EMG), generated from the remaining muscles in the stump of the user (see Myoelectric control chapter below). Electrically-powered prostheses offer a large range of design, grip force and precision, but they lack of sensory feedback and can be quite expensive depending of the model. In the last decade, a number of more advanced prosthetic hand have emerged, providing control of multiple degrees of freedom of the hand, and in some cases providing control of each finger separately. However, these advanced prostheses are bound to the current state of the art in EMG control systems (see state of the art of myoelectric control chapter below).
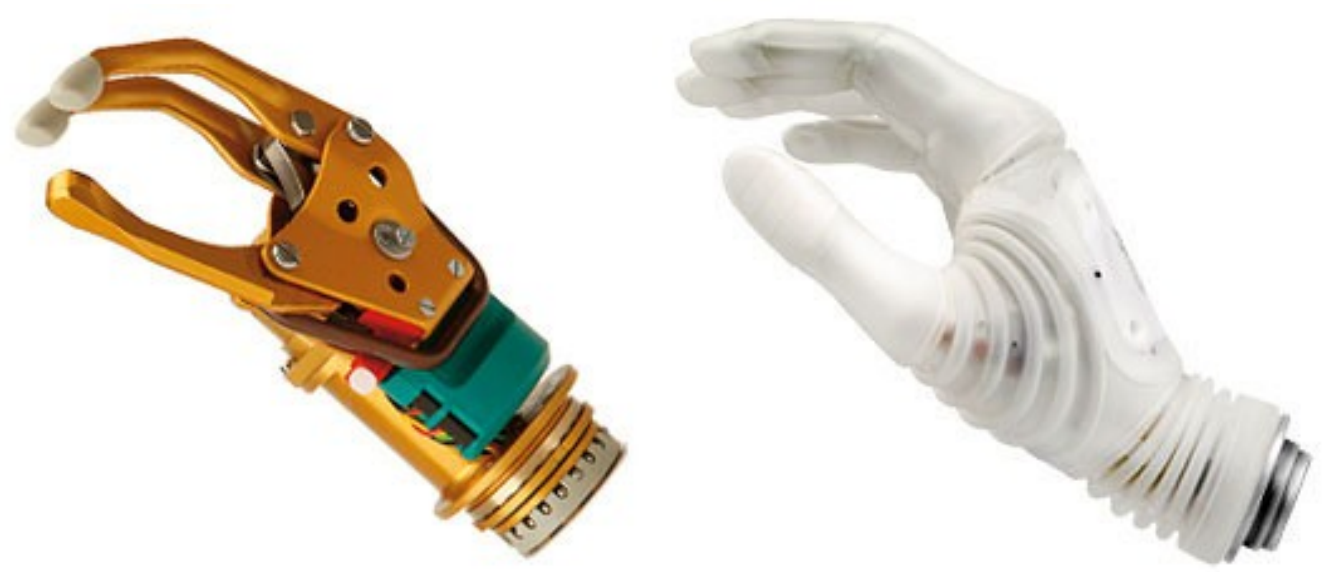

Fig.4: Example of electrically powered prostheses (Images courtesy of Ottobock GmbH). (a) MyoHand VariPlus Speed [7]. (b) Michelangelo hand [8]. 


\section{Control of prostheses}

As described above, a large variety of active prosthetic hands (and corresponding wrists) have been developed through years of research and engineering. The main limitation of these devices remains their control method. Operate a prosthesis requires an alternative control method to replace the muscles and tendons of the hand and wrist. Many methods have been investigated to restore control of hand functions. These methods can be subdivided in two main groups whether they link a valid motion to the control of the hand or not. Two very common approaches are described in the following, each corresponding to a different group.

\section{Body powered}

The body-powered prostheses offer in most cases one degree of freedom of the hand, the grip. The control is often made using the shoulder blades [9] (in some cases the chest, or using a back anchor [10]). Once harnessed, pulling the shoulder blades will pull a cable attached on the harness, and activate the prostheses. Two designs are available for the control of the hand, a voluntary closing design, and voluntary opening design. In the voluntary closing design, the prosthesis is opened by default (at rest), and the cable activation controls the closing of the hand. This setting allows control of the force exerted by the closing hand [11]. In the voluntary opening design, the hand is closed by default (at rest), and the cable activation controls the opening of the hand. This setting does not allow to control the force exerted in closing, but does not require maintained contraction to hold closing, thus is often preferred by users to limit fatigue.

The body-powered control approach offers reliable control of the hand, and provides the user with some natural sensory feedback through the tension of the cable. However, this approach relies on a valid motion of the user, linking this motion with the operating of the hand. This can result in discomfort, limitation of user's mobility and long term problems due to extensive use of the corresponding body parts. In addition, this design only allows the control of one degree of freedom of the hand, and cannot be used to control more complex hands with multiple degrees of freedom.

\section{Myoelectric control}

Myoelectric control consists in using EMG signals to determine user's intensions, and control the prosthesis.

\section{EMG signals}

EMG signals correspond to recordings of electrical potentials generated by activity in muscles. These signals can be recorded at the surface of the skin (surface EMG), or from inside the muscles (intramuscular EMG). Intramuscular EMG signals are seldom used outside of research area, mainly due to their invasiveness. On the contrary, surface EMG signals have been largely used, in both research and commercial products. 
Surface EMG signals reflect the electrical activity of the muscles within the detection volume of the electrode. They consist of a sum of action potential resulting of motor unit firing [12]. The spectrum of interest in surface EMG goes from $10 \mathrm{~Hz}$ to $1 \mathrm{kHz}$, although most relevant activity lies below 400Hz [13].
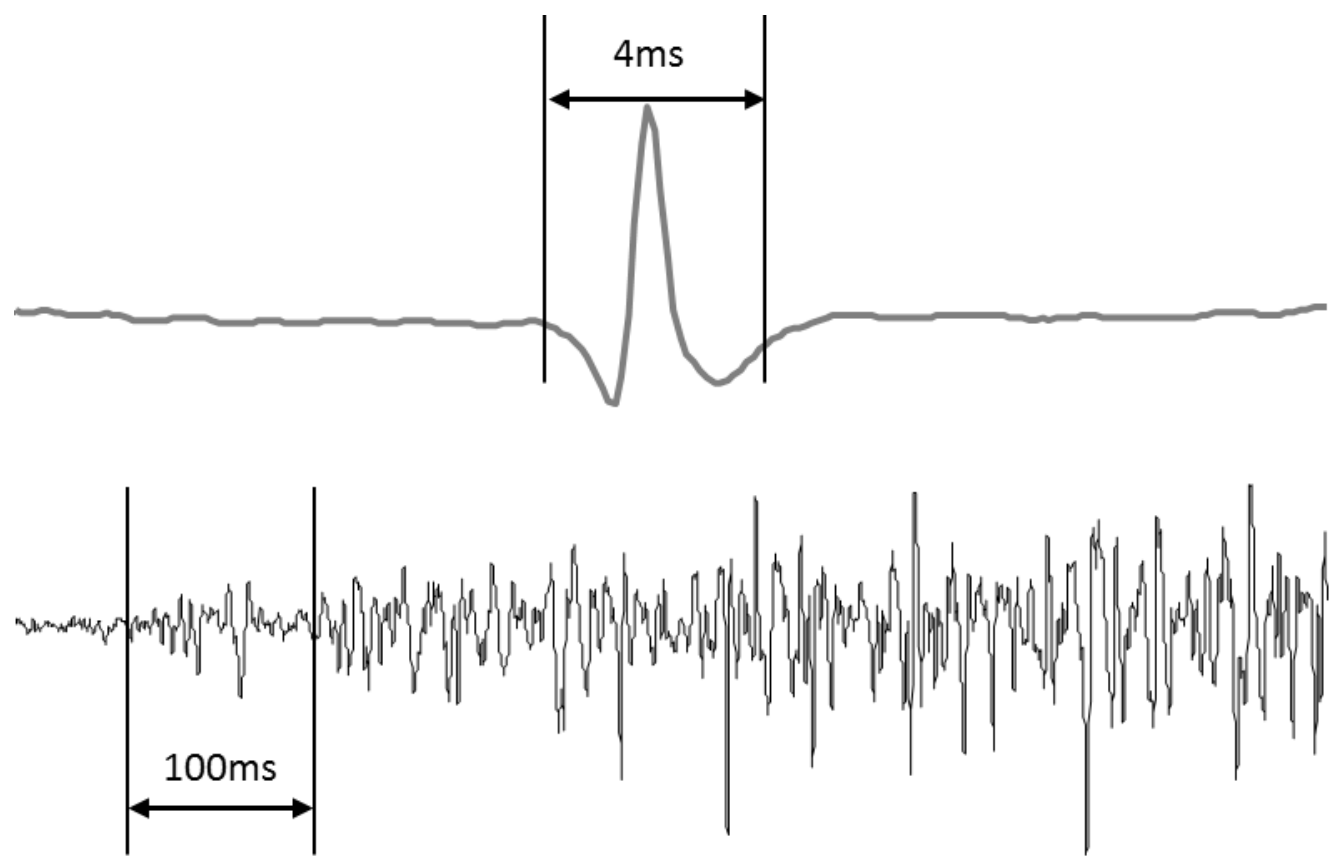

Fix. 5: Example of action potential from intramuscular recording (upper line), and surface EMG recording (bottom line)

Surface EMG can be recorded in monopolar settings, or bipolar setting. In bipolar setting, two electrodes are placed on top of the muscle(s), aligned with the muscle fibers, and the recorded signal corresponds to the difference between the two recorded potentials. In monopolar setting, one electrode is placed on the muscle(s), and a reference electrode is placed on the patient away from muscular activity (i.e. nearby an articulation). The signals from both settings have zero mean and correlated variance with corresponding muscles activity. The monopolar recordings are known to offer less distorted signals compared to bipolar recordings [14]. In research both settings have shown to be similarly suitable for myoelectric control [15], most often with "pre-gelled" one time use electrodes. The bipolar setting is favored in commercial application as the recording sites are paired and closely situated, allowing easier and smaller designs of "dry" electrodes. 
(a)

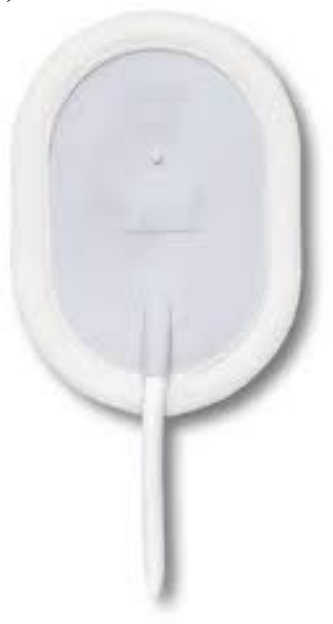

(b)

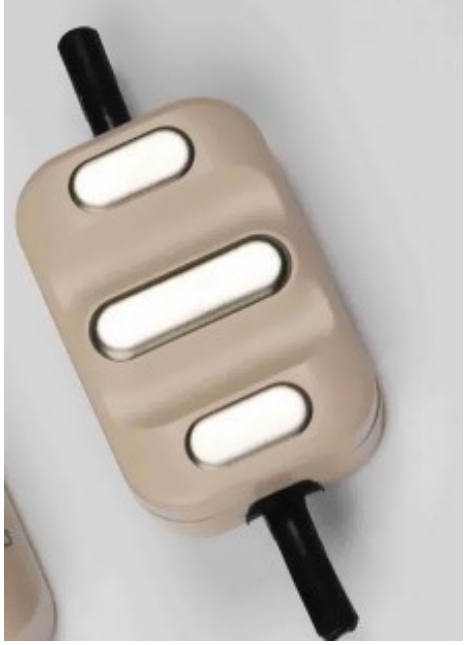

Fig. 6: (a) Example of pre-gelled electrode used for surface EMG recording (Ambu A/S - neuroline). (b) Example of dry electrode to be mounted on sockets (courtesy of Ottobock $\mathrm{GmbH}$ )

Surface EMG have the interesting property of increasing variance along with muscles activity. However, they are influenced by many factors, such as electrode/skin contact quality, fatigue, between muscles cross talk. All these factors limit the stability of the signals.

\section{Myoelectric application}

After amputation, some muscles remain in the stump of the patient, most often attached on one end to bones during the surgery. Surface EMG recorded from the stump can still reflect some of the patient's intension regarding his lost limb. By translating the surface EMG signals into user's intension, myoelectric algorithms allow more natural control of prostheses compared to body-powered control. In addition, myoelectric control does not rely on any other motion of the body.

Many approaches have been investigated to translate surface EMG signals into prostheses instructions, with various degrees of success (see State of art chapter below). Each patient is different (stump length, shape, scars...) and can require adaptations in the control algorithm (thresholds values, number of recording sites available). Due to this variety, most algorithms are first tested with healthy subjects within research projects. Once they have shown to be relevant for applications, additional investigations are made involving amputees. These tests with amputee often lead to similar behavior with slightly lower performance compared to healthy subjects [16]. 


\section{State of art of myoelectric control}

Myoelectric control of prostheses has been investigated for many years [17], resulting in commercial products available to patients. However, the control system remains the bottleneck of hand replacement prostheses [18]. In this chapter the most common commercial myoelectric control systems and research approaches are reviewed.

\section{In commercial products}

In commercial products, the surface EMG signals are recorded from one or two sites (in bipolar setting). The control systems provide control of a number of functions. The number of function available depends of the system and vary from a single function (one site system), to multiple degrees of freedom (often 2DoFs, two sites system).

A one site system (one surface EMG channel) can either control one or two functions. The surface EMG activity is compared to one or two thresholds in order to operate the hand. When controlling one function, the control method is similar to the body-powered control method (voluntary opening, or voluntary closing), and surface EMG activity higher than the threshold results in operating the hand. In order to control two functions with a one site system, two thresholds are used to define a "low activity" level and a "high activity" level, and each activity level is assigned to one function.

Two sites systems (two surface EMG channels) provide control of more functions, and in most cases offer proportional control of the corresponding functions. Each surface EMG channel is assigned to one function. Activating the channel will operate the corresponding function. When proportional control is used, higher surface EMG activity results in higher velocity. In order to control more functions for complex hands, a switch strategy is often implemented. A threshold is then defined for each channel. When the surface EMG activity exceeds the threshold in both channels, the functions controlled by each of the channels are changed. This approach potentially allows controlling an infinite number of functions. However, the transitions between the different functions remain unpractical, as a sequential number of actions must be performed to ensure the control of the desired function set. In most cases, the number of function is limited to four (2Dofs). Common controlled functions are: hand opening/closing, wrist supination/pronation, wrist flexion/extension, grasping type lateral/opposed.

\section{In research}

In research, more advanced processing methods have been investigated to improve the ability of myoelectric controllers, enhance the number of classes, and bring a more natural control to the users. With these systems, the number of recorded surface EMG channels varies from a few channels (4 to 6 channels) to hundreds of 
channels with High density EMG recordings $[15,19]$. The processing of this potentially large amount of data is divided in two main approaches: pattern recognition, and estimation.

\section{Pattern recognition}

The pattern recognition approach consists in identify pattern in the surface EMG channels and assign them to each desired function. This is usually done during an initial training. The system is then able to recognize user's intentions by matching the surface EMG with the pattern identified during training. The main assumption of this approach is that there are distinct and consistent patterns in the surface EMG channels for each function, so that a classifier can be trained to identify them. Pattern recognition systems consist of two primary steps: feature extraction, and classification as shown in Fig.7.

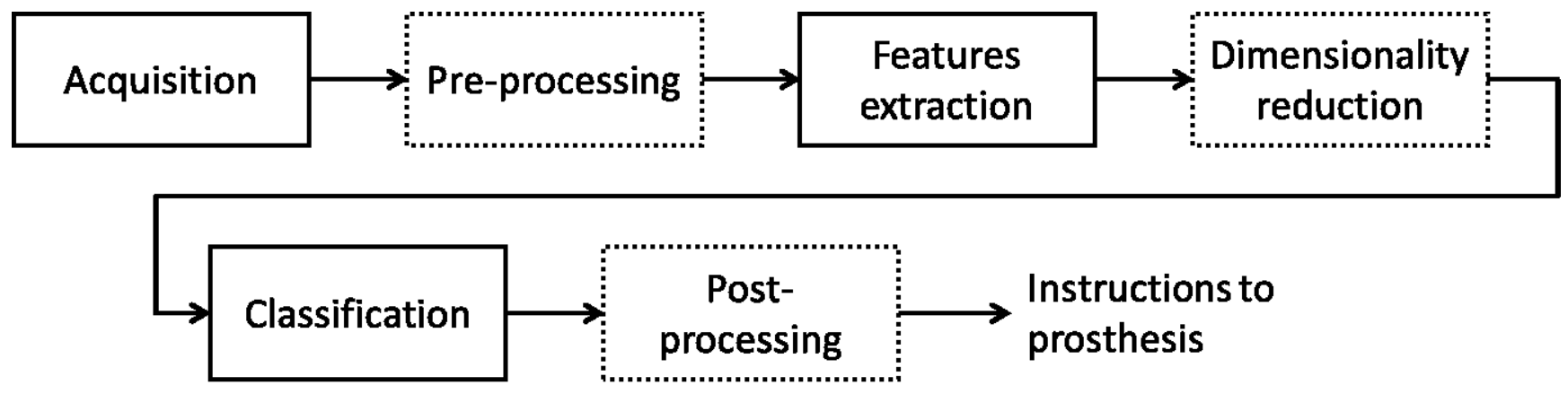

Fig. 7: Pattern recognition control block diagram

Feature extraction consists in extracting relevant properties of the signals. Over the years, large numbers of features have been investigated for myoelectric control [20-23]. During classification, the extracted features are used to determine the intended function. Various types of classifiers [21,24-29] have been used for this purpose, showing promising performance. Along with feature extraction and classification, the performance of pattern recognition algorithm is dependent of the number and position of the electrodes [19], dimensionality reduction [30,31], and the relevance of the data used for training of the classifier [32,33]. Other external factors are known to influence the surface EMG recorded on the forearm and thus the performance of the pattern recognition, i.e. arm position [33] and fatigue [34]. Although accurate classification of motions has been achieved using pattern-recognition [15,16,21], the translation to clinical applications remains very limited [35].

\section{Estimation}

The estimation approach is more recent than the pattern recognition and is based on the concept of muscles synergy [36]. It attempts to directly translate the surface EMG channels into proportional angular instructions to the prostheses. This is usually done using biomechanics data in order to match surface EMG data 
corresponding motions or force. Various algorithms, such as non-negative matric factorization [37], Bayesian network [38], or Artificial neural network [39] have been used to match the surface EMG signals with the motions. This approach has shown promising results, allowing simultaneous and proportional estimation of force for multiple degrees of freedom of the hand and wrist [40]. However, this new approach suffers from one main drawback: it requires substantial biomechanics data synchronized with the surface EMG data. More investigation will be required to determine the clinical potential of this approach and the reliability of the control.

\section{What is missing?}

Despite all hand prostheses and control methods developed in the last decade, a gap remains between research studies outcome and commercial products. There are multiple reasons for this gap. Many research projects use myoelectric data recorded during a short set of tasks, to determine offline classification accuracy, or reconstruction accuracy. Accuracy of algorithms reflects the ability to provide the right control output. However, it does not take into account the requirements of the algorithms in term of training or real time processing, and is often based on data recorded in ideal conditions. In a commercial product, the processing needs to be done online, at any time, and with neither lag, nor freeze due to processing. This is a major limit, as more complex algorithms require more computational power, which affect battery life on the devices. In addition, a commercial product needs to be reliable to be accepted and used by the patients. Some control algorithms can provide very good control, in most situations, but at the cost of large amount of training data, and time consuming complex optimization, which is not suitable in commercial applications. The reliability of nearly all algorithms available depends on the training given to the algorithm. With limited training data, current algorithms often turn unreliable with long term use (multiple hours), or with surrounding changes (arm position, load, sweat).

\section{Development}

The overall objective of this $\mathrm{PhD}$ project was to provide a natural and intuitive, yet reliable myoelectric control system. The work of this $\mathrm{PhD}$ project was divided in three studies. In the following, the motivations and main outcome of each study are described.

\section{Study 1}

In the initial stage of this $\mathrm{PhD}$ project, the state of the art of myoelectric control in research was mainly focused on pattern recognition. Numerous studies could be found regarding features selection and classification, as well as multiple pre and post-processing techniques to improve classification. However, 
most of these investigations were made during static repeated contractions, disregarding a major factor: the dynamic situations during daily use. Indeed, studies have shown very promising results on static surface EMG signals, but very limited investigations had been performed involving dynamic signals, during transition.

\section{The first study of this PhD project investigated the performance of current pattern recognition systems} on a dynamic situation. Particular focus was given to the impact of the training data selection.

This study showed that accurate classification can be achieved with traditional pattern recognition system when using the proper training data, and threshold pre-processing. However, the main conclusion of this investigation was that the data used to train the algorithms need to be relevant to situations of use in order to obtain reliable classification. Another example leading to this conclusion can be found in [33], where the training data are required to cover the various potential position of the arm in order to ensure acceptable performance. While this approach provides a potential solution, it is important to notice that surface EMG are known to change in time, with electrode replacement, fatigue, etc. Thus it seems rather difficult to include every possible situation of use during the training of commercial products that would need to be retrained every day, or multiple times a day depending of the situation (warm weather, humidity...). In conclusion, traditional pattern recognition system could be used on dynamic situation, as shown in this study, but at the cost of additional training. 


\section{Study 2 \& 3}

Traditional pattern recognition systems use the most recent data (usually 100 to 250ms) to determine the current user's intention. However, neither the history of classification nor the evolution of the signal that preceded these recent data is used to determine the command. Thus the classification is a purely instantaneous process, relying exclusively on the recent data and training procedure. While there have been some attempts to use the history of the classification [41,42], these are post processing methods, and the core of the system remain instantaneous.

In order to minimize the dependence to training, and provide increased reliability, an alternative control system was developed, using a state-based approach. In the proposed system, each function to be operated is assigned to a state. The active function is determined by the active state, and remains active until a transition is required. To decide of a transition, the system uses the recent data, along with "long term" data representing the overall activity in the current state. The block diagram of the state-based system is shown in Fig.8

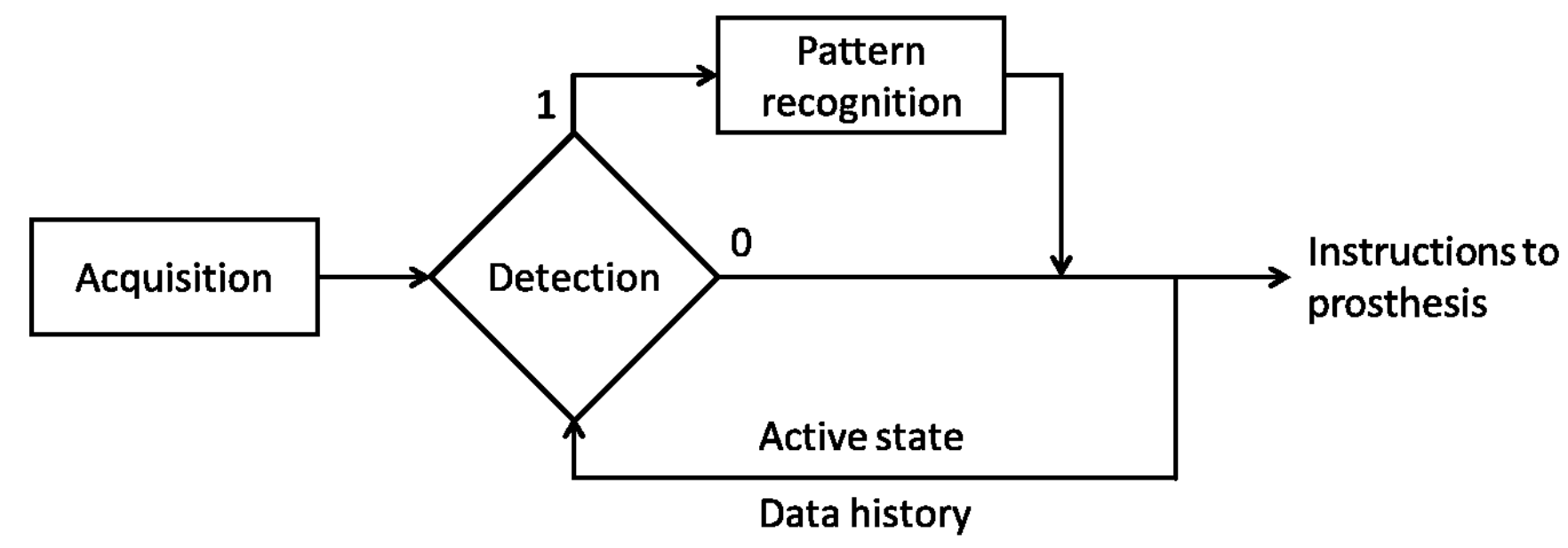

Fig. 8: State based control block diagram

The transitions between states were based on two steps: detection and classification. The detection determined the activity in the current state, and compared it with the activity in the recent data. By increasing the length the recent data window, the detection method could reliably determine if an increase of activity was observed in the surface EMG channels compared to the state activity level. In that case a change of state was required, and the new state to be activated was determined by classification.

The second study of this PhD project presented a state-based system for myoelectric control. The performance of the system was compared with a traditional pattern recognition system on dynamic situations. 
The proposed system showed promising performance compared to the traditional pattern recognition system, mainly due to a substantial reduction of inconsistencies during steady states. However, these results were obtained during offline processing, with a large amount of training data, and no proportional control was generated.

Thus in further development, the system was substantially improved by adapting and optimizing the transition method to operate in real time, and proportional activation of the functions was implemented.

The third study presented the online and proportional state-based system. The online performance of the system was evaluated on both positioning and force controlling tasks, with very short training.

In this study, the proposed system allowed the subjects to precisely control both the position of two degrees of freedom, and the force during grasping. 


\section{Conclusion}

The design of replacement prostheses for upper extremities, and particularly trans-radial, amputees has gained renewed interest in the last decades due to the progress in the development of dexterous multifunctional hand replacement prostheses. This thesis work focused on reducing the gap between commercial control systems available to patients, and the systems described in research studies. The pattern recognition systems as described in most studies can provide intuitive control of multiple degrees of freedom. However, the dependence of these systems to training, and thus their limitation in reliability has prevented their translation into clinical products for transradial amputees.

In this thesis, an alternative approach to pattern recognition was developed, using a state-based approach for myoelectric control. The main idea behind this approach was to include the current status of control into the decision process. This was done defining a level of activity in the current active function, and use this information to determine if any change in the control was required. The results of this $\mathrm{PhD}$ project showed that this approach allowed accurate proportional control of two degrees of freedom, with an intuitive switching strategy.

Most commercial systems are limited to two degrees of freedom, with unintuitive switching between the controls of the functions. Thus the proposed system focused on two degrees of freedom of the wrist and hand. However, there is no limitation in number of functions in the design of the system, and it is expected that, with appropriate training and electrode setting, the proposed system could provide control of more degrees of freedom, with limited impact on the reliability.

In this project, the proposed system was shown to be a potentially suitable alternative to current commercial myoelectric control scheme. In future work, the proposed system will be provided to myoelectric users as a replacement for their usual switching method. In addition, investigations toward the inclusion of more degrees of freedom will be performed, in order to match the available hands. 


\section{References}

[1] Lundborg G. "Tomorrow's artificial hand." Scandinavian Journal of Plastic and Reconstructive Surgery and Hand Surgery 2000;34(2):97-100.

[2] Bailey AA, Moersch FP. "Phantom limb." Can Med Assoc J 1941;45(1):37.

[3] Mercier C, Sirigu A. "Training with virtual visual feedback to alleviate phantom limb pain." Neurorehabil Neural Repair 2009;23(6):587-594.

[4] Burger,H. "Perspective Of A Prm Specialist On Rehabilitation Of Persons Following Upper Limb Amputation." Canada: Myoelectric Symposium; 2011.

[5] Single-Cable System Hand. Available at:

http://www.ottobock.com/cps/rde/xchg/ob com en/hs.xsl/6970.html. Accessed 12/12, 2012.

[6] Hooks. Available at: http://www.ottobock.com/cps/rde/xchg/ob com en/hs.xsl/6914.html. Accessed 12/12, 2012.

[7] MyoHand VariPlus Speed. Available at: http://www.ottobock.com/cps/rde/xchg/ob com en/hs.xsl/19992.html. Accessed 12/12, 2012.

[8] Michelangelo hand. Available at: http://www.ottobock.com/cps/rde/xchg/ob com en/hs.xsl/49490.html. Accessed 12/12, 2012.

[9] Doeringer JA, Hogan N. "Performance of above elbow body-powered prostheses in visually guided unconstrained motion tasks." Biomedical Engineering, IEEE Transactions on 1995;42(6):621-631.

[10] Latour,D and Martino,GP. "Creative Solutions To Bilateral Upper Extremity Involvement." Canada: Myoelectric Symposium; 2011.

[11] Smit G, Plettenburg DH. "Efficiency of voluntary closing hand and hook prostheses." Prosthet Orthot Int 2010;34(4):411-427.

[12] Farina D, Merletti R, Enoka RM. "The extraction of neural strategies from the surface EMG." J Appl Physiol 2004;96(4):1486-1495.

[13] Barbero M, Merletti R, Rainoldi A. Atlas of Muscle Innervation Zones. Italy: Springer; 2012.

[14] Gabriel DA. "Effects of monopolar and bipolar electrode configurations on surface EMG spike analysis." Med Eng Phys 2011;33(9):1079-1085.

[15] Daley H, Englehart KB, Hargrove LJ, Kuruganti U. "High density electromyography data of normally limbed and transradial amputee subjects for multifunction prosthetic control." Journal of Electromyography and Kinesiology 2012 6;22(3):478-484.

[16] Hargrove LJ, Li G, Englehart KB, Hudgins BS. "Principal components analysis preprocessing for improved classification accuracies in pattern-recognition-based myoelectric control." IEEE Trans Biomed Eng 2009;56(5):1407-1414. 
[17] Parker PA, Scott R. "Myoelectric control of prostheses." Crit Rev Biomed Eng 1986;13(4):283.

[18] Jiang N, Falla D, d'Avella A, Graimann B, Farina D. "Myoelectric control in neurorehabilitation." Crit Rev Biomed Eng 2010;38(4):381-391.

[19] Farrell TR, Weir R. "A comparison of the effects of electrode implantation and targeting on pattern classification accuracy for prosthesis control." IEEE Trans Biomed Eng 2008;55(9):2198-2211.

[20] Lee S, Kim J, Park S. "An enhanced feature extraction algorithm for EMG pattern classification." Rehabilitation Engineering, IEEE Transactions on 1996;4(4):439-443.

[21] Englehart KB, Hudgins BS, Chan ADC. "Continuous multifunction myoelectric control using pattern recognition." Technology and Disability 2003;15(2):95-103.

[22] Englehart KB, Hudgins BS, Parker PA, Stevenson M. "Classification of the myoelectric signal using time-frequency based representations." Med Eng Phys 1999;21(6-7):431-438.

[23] Englehart KB, Hudgins BS, Parker PA. "A Wavelet Based Continuous Classification Scheme for Multifunction Myoelectric Control." IEEE Transactions on Biomedical Engineering 2001;48(3):302-311.

[24] Ajiboye AB, Weir RF. "A heuristic fuzzy logic approach to EMG pattern recognition for multifunctional prosthesis control." IEEE transactions on neural systems and rehabilitation engineering 2005;13(3):280-291.

[25] Huang Y, Englehart KB, Hudgins B, Chan ADC. "A Gaussian mixture model based classification scheme for myoelectric control of powered upper limb prostheses." IEEE Trans Biomed Eng 2005;52(11):1801-1811.

[26] Chan ADC, Englehart KB. "Continuous myoelectric control for powered prostheses using hidden Markov models." IEEE Transactions on Biomedical Engineering 2005;52(1):121-124.

[27] Lucas MF, Gaufriau A, Pascual S, Doncarli C, Farina D. "Multi-channel surface EMG classification using support vector machines and signal-based wavelet optimization." Biomedical Signal Processing and Control 2008;3(2):169-174.

[28] Dening DC, Gray FG, Haralick RM. "Prosthesis control using a nearest neighbor electromyographic pattern classifier." Biomedical Engineering, IEEE Transactions on 1983(6):356-360.

[29] Gallant PJ, Morin EL, Peppard LE. "Feature-based classification of myoelectric signals using artificial neural networks." Medical and Biological Engineering and Computing 1998;36(4):485-489.

[30] Hargrove LJ, Scheme E, Englehart KB, Hudgins BS. "Principal components analysis tuning for improved myoelectric control." 2007.

[31] Du YC, Shyu LY, Hu WC. "The Effect of Combining Stationary Wavelet Transform and Independent Component Analysis in the Multichannel SEMGs Hand Motion Identification System." Journal of Medical and Biological Engineering 2006;26(1).

[32] Lorrain T, Jiang N, Farina D. "Influence of the training set on the accuracy of surface EMG classification in dynamic contractions for the control of multifunction prostheses." J Neuroeng Rehabil 2011;8(1):25. 
[33] Fougner A, Scheme E, Chan A, Englehart KB, Stavdahl O. "Resolving the Limb Position Effect in Myoelectric Pattern Recognition." IEEE Trans Neural Syst Rehabil Eng 2011;19(99):644-651.

[34] Asghari Oskoei M, Hu H. "Myoelectric control systems-A survey." Biomedical Signal Processing and Control 2007;2(4):275-294.

[35] Jiang N, Dosen S, Müller KR, Farina D. "Myoelectric control of artificial limbs: is there the need for a change of focus?" IEEE Signal Process Mag 2012.

[36] Bizzi E, Mussa-Ivaldi FA, Giszter S. "Computations underlying the execution of movement: a biological perspective." Science 1991;253(5017):287-291.

[37] Muceli S, Boye AT, d'Avella A, Farina D. "Identifying representative synergy matrices for describing muscular activation pattern during multi-directional reaching in the horizontal plane." J Neurophysiol 2010:00559.2009.

[38] Li J, Wang ZJ, Eng JJ, McKeown MJ. "Bayesian Network Modeling for Discovering "Dependent Synergies" Among Muscles in Reaching Movements." IEEE Transactions on Biomedical Engineering 2008;55(1):298-310.

[39] Kamavuako EN, Englehart KB, Jensen W, Farina D. "Simultaneous and Proportional Force Estimation in Multiple Degrees of Freedom From Intramuscular EMG." IEEE TMBE 2012;59(7):1804-1807.

[40] Nielsen JLG, Holmgaard S, Jiang N, Englehart KB, Farina D, Parker PA. "Simultaneous and proportional force estimation for multifunction myoelectric prostheses using mirrored bilateral training." IEEE Trans Biomed Eng 2011;58(3):681-688.

[41] Englehart KB, Hudgins BS. "A robust, real-time control scheme for multifunction myoelectric control." IEEE Trans Biomed Eng 2003;50(7):848-854.

[42] Simon AM, Hargrove LJ, Lock BA, Kuiken TA. "A decision-based velocity ramp for minimizing the effect of misclassifications during real-time pattern recognition control." IEEE Trans Biomed Eng 2011;58(8):23602368. 
A part of this thesis has been removed from this publication due to copyright. 